\title{
MUSIC PERFORMANCE ANXIETY IN ADOLESCENT STUDENT SINGERS
}

Research in partial fulfilment of the requirements for MMUS

Megan Corby 


\begin{abstract}
This project seeks to sidestep the debilitating effects of music performance anxiety by cross-referencing knowledge from the areas of adolescent psychology with literature on MPA in singers in general in order to target adolescent singers early in their training. As well as considering the causes, symptoms and treatment of music performance anxiety, the project examines the role of the natural anxieties of adolescence in triggering music performance anxiety and seeks to chart a way through. Its intended readership is the classical singing teacher.
\end{abstract}




\section{Music Performance Anxiety in Adolescent Student Singers}

\section{Introduction}

The goals of musical performance are various. They include such aspirations as authentic communication with an audience, self-expression, a sense of achievement, self-development, a desire to please others and both musical and poetical appreciation and enjoyment. These are positive, and imply enjoyment for both the singer and the audience. Some of the beauty in singing lies in the uniqueness of every voice and every performance. No matter whether it is the music, the poetry, the musicianship, the timbre of the voice, the emotion, or some indefinable quality of the performer that moves the audience, the common thread is the need for self-knowledge and personal commitment and enjoyment from a singer. The invisible connection between the singer and the music can be interrupted by self-doubt and audiences can instinctively feel the negative effect of tension on a performance. Certainly no singer wants to suffer from music performance anxiety (hereafter referred to as MPA), but to some singers, a performance without it is merely fantasy. Even those who have experienced anxiety-free performances in the past may struggle for the rest of their life to recapture that experience. To sing is to share a part of our humanity and ourselves. It requires integrity and self-knowledge to affect an audience with the voice.

Commonly known as stage fright, MPA is a distressed response to the act of live performance. It can occur at any time before, during and/or after performance. Although it may be described as a sense of uneasiness or apprehension, it is more than just a feeling (Ladd, 2006, p.343). Stress is the body's non-specific response to any demand (Selye, 1974, p.27). It doesn't matter if the demand is pleasant or unpleasant as the body responds in the same way with readjustments designed to return the body to normal function. The body's response has physiological, cognitive and behavioural components.

Many singers commence lessons in their adolescence. The impetus to sing usually comes from the student rather than external influence and it is not until adolescence that the drive has developed sufficiently for parents to consider training. 
Accompanying their relative inexperience in performing is a narrower range of coping skills and less confidence than adults. In many cases, a teacher is responsible for someone's first public performance, but many singers don't continue to sing and perform past their adolescence. Our society does not make it easy for the adult singer to continue performing, with few opportunities socially and few rewards professionally. Teachers have a small window to provide positive performance experiences in adolescence, as once a singer reaches adulthood they need a high level of motivation to continue singing. Vocal teachers need to be to be thoroughly versed in performance preparation, post-performance support, and techniques for preventing and managing music performance anxiety early on in a singer's training.

Musical performance is an ideal method of providing controlled, short-term, moderate amounts of anxiety for an adolescent to learn new methods of adjusting to their environments. Training is usually done individually with an adult; the complex combination of factors and expressions of anxiety can be managed through repertoire choices, variety, timing and significance of performance experiences. The existence of MPA is typically apparent, as an adolescent singer experiencing too much stress often has physical manifestations of anxiety and vocal quality is adversely and audibly affected. The assessment of the student who suffers distress due to their performing which affects their ability to function in other areas in their life is more complicated. Open communication with family is therefore vital to ensuring the appropriate level of challenge is consistently provided.

This essay explores music performance anxiety; its nature and effect on the vocal performance of adolescent singers. The study is limited to formal vocal training that provides classical technique. This technique requires free and healthy sound production whether it is employed in the singing of classical, opera or legitimate musical theatre styles. The goals of formal vocal training are to give the adolescent singer control over their performance, their singing experience and for their ability not to be defined by performance anxiety.

The study begins by investigating adolescence. The rapid development at this time encompasses many spheres of existence: cognitive, emotional, spiritual, physiological, behavioural and social. How do vocal performance, adolescent 
development and the occurrence of anxiety affect each other? The particular vulnerabilities of adolescent singers are also outlined and discussed.

Chapter 2 defines music performance anxiety. It examines types of stress, its evolutionary role in human adaptation, assisting in the development of coping systems. The difference between stress and anxiety is noted before focusing on the specific symptoms of MPA.

Chapter 3 focuses on the causes of MPA in adolescent singers and what factors may initiate its presence in this age group. The triggers may be either external or internal. Various emotional states, which may be conducive to MPA, are divided into categories according to various developmental theories. Chapter 4 puts forward ideas about learning and the importance of effective assessment of the many variables of MPA in adolescent singers. Strategies for managing and preventing MPA are described.

The project concludes with a description of optimal performance where freedom of expression is not impacted by the negative effects of music performance anxiety. Discussion subjects include the potential impact of the parental bond, maintaining students' interest in their training and whether adolescent singers are particularly vulnerable to MPA. The crucial interaction between voice teachers and adolescent singers is given attention and whether it can actively disrupt the development and continued existence of MPA. Finally, the place MPA occupies in vocal pedagogy is questioned. Is our approach developing in much the same way as other strands of our teaching? What should our attitude to MPA be? The discussion raises even more questions as to how the information about MPA should be taught and disseminated. Is there a way that the information and techniques can reach adolescents in the private studio where it is needed most? What form should the information take?

Although MPA is a natural response to the stress of vocal performance, it is not a given. The study of music is beneficial to development whether the student intends a musical career or not. The purpose of this study is to direct adolescents and their teachers who are affected by MPA towards strategies that enable each singer to maximize their potential and the many personal benefits that singing offers. 


\section{Chapter 1: Adolescence}

\section{Definition}

For the purpose of this essay, adolescence will be assumed as spanning the years from the onset of puberty (around 10 years of age) until the early twenties (approximately up to the age of 22). There is no consensus with respect to these parameters, a reflection perhaps of modern Western society's apparent lack of clear age-related milestones, or 'rites of passage'. The World Health Organization (WHO), for example, defines adolescence as the period of life between 10 and 19 years of age (Goodburn, 1995), a definition confirmed in 1998 and followed by most other organizations within the United Nations. The WHO acknowledges the imprecision of these stated parameters, accepting that "the dynamic transitions of this stage of life have as much to do with biological aspects as with socio-cultural conditions." (WHO, p.1). Interestingly, the WHO's parameters for adolescence lie centrally between those it sets for 'youth' (15-24yrs) and 'young people' (10-24 yrs). Balk (1995, p.5), an American university professor specialising in adolescence, extends the upper parameter to the age of 22 and divides adolescence into three periods: early (10$14 \mathrm{yrs})$, middle (15-17yrs), and late (18-22yrs). Another approach is taken by behavioural scientists who use the term 'adolescence' when describing the psychological and sociological profile that is proposed to distinctly characterize the transitional years. In this case age is an unreliable predictor. Travers (2006, p.4) explains: "Age may give a rough estimate of when behavior appears, but it tells us nothing about why a particular behavior appears at a specific time ... The answers still remain hidden in the interactions among the various developmental forces acting on a person". Depending upon a number of factors including biological, cognitive and social development, adolescence is deemed to end when the person is fully independent and operational as an adult.

The study of adolescence as a scientific academic discipline is a recent one, first set in motion by G. Stanley Hall's two-volume work Adolescence (1904) (Berzonsky, 2000, p.11). In this work, Hall paralleled human development with the stages of human 
evolution. Adolescence, in his view, equated with the rise of civilisation and its increasing dominance of chaos (Balk, 1995, p.10). The adolescent's internal struggle between selfish desires and social good created the turbulence of the popularly held theme of adolescence as a time of storm and stress (Berzonsky, 2000, p.12). The concept resonated with the intellectual imagination of the day and Sturm und Drang was idealised in the literature, art and music of the period. In the Twentieth Century the concept was re-interpreted as teenage rebellion with the advent of Rock and Roll in the 1950s. Even today the particular experience of adolescence is a distinct marker within the span of human development and, as such, emphasizes generational differences. Hall partnered turmoil and conflict with hope and optimism in his attitude towards the transitional period of adolescence.

\section{Physical changes during adolescence}

Adolescence typically begins with the onset of puberty, the physical transition triggered by a surge of hormones, when a child develops secondary sex characteristics such as breasts and hips in girls and a deeper voice in boys. The onset of puberty varies between individuals and races due to differences in genetic, environmental and cultural factors. Girls tend to enter puberty two years earlier than boys if measured by sexual reproductive capabilities, specifically, menarche for girls at approximately 12.5 years (Paikoff \& Brooks-Gunn, 1991) and sperm production for boys at around 15 years of age (Balk, 1995, p.49).

The rapid physical growth that takes place during adolescence may lead to a decline in coordination and loss of balance. This may last for up to six months at a time, as the neurological systems struggle to keep pace with musculo-skeletal growth spurts (Eckrich and Strohmeyer, 2005, p 180). The awkwardness that results is more frequently associated with males (Beunan \& Malina, 1988). The timing of the growth spurts is generally two years earlier for girls, beginning before adolescence, between 8.7 and 10.3 years of age, and for boys, between 10.3 and 12.1 years of age (Balk, 1995, p.47). Males improve their motor performance throughout adolescence while females reach peak development at 14 years of age (Haubenstricker, Wisner, Seefeldt, \& Branta, 1997). Both the individual and society's subjective response to the biological changes that constitute maturation are affected by self-image and selfesteem (Sprinthall \& Collins, 1984, p.76). 


\section{Psychological changes in adolescence}

In his Eight Stages of Psychosocial Development of 1950, the German developmental psychologist and psychoanalyst Erikson (1902-1994) interpreted the turmoil of adolescence as arising from the need to develop a sense of identity. The adolescent does this by attempting to balance personal changes with the changing societal demands on his age group. If successful, the adolescent achieves a clearer sense of identity (Berzonsky 2000, p. 20). Those who have unsuccessfully resolved crises from the previous four stages of development may experience 'identity diffusion', a difficulty or inability to make choices that strengthen the concept of self rather than allowing others to define it. Identity diffusion commonly leads to confusion: such adolescents are at higher risk of withdrawing, running away or turning to drugs (Travers, 2006, p.10) and in later life are typically unable to make commitments, whether in their career or in their personal relationships. Characteristics of the adolescent undergoing identity formation include the temporary assumption of different identities with the attendant lack of expectation of having to take full responsibilities for the consequences of any particular one. Erikson believes that indecision is important at this time, and tolerance from those around helps lead to a positive identity.

\section{Cognitive development during adolescence}

In 1958 Piaget (1896-1980), a Swiss developmental psychologist, observed that formal operational thinking, the ability to move beyond reality into the realm of hypothetical ideas develops in adolescence. Formal operational thinking enables adolescents not only to think about what happened and why it happened (Berzonsky, 2000, p.23), but also how to process the different effects multiple factors will have on an outcome. Formal operational thinking is aided by the development of metacognition (typically from the age of 12 years) that is the ability to think about one's own thinking processes. Cognitive structures are developed by adapting and organizing the stimuli received from the environment: the more differentiated an adolescent's structures and stimuli, the more effectively they can problem-solve (Berzonsky, 2000). The changes in thought process are necessary to assimilate and understand interactions with the environment that are incomprehensible with the current cognitive structure. Characteristics of formal operations are systematic thinking and the ability to consider competing points of view (Balk, 1995, p.111). 


\section{Cognitive-behavioural development in adolescence}

American professor and psychologist David Elkind (1931- ) looked for ways to reconcile the development of cognitive structures with behaviour typical of each stage (1967). He theorized that each stage of cognitive development has a period of egocentrism where a person is tied to his or her own point of view. According to Elkind, adolescents are tied to their own conceptual perspective; they are preoccupied with themselves and believe everyone around them is too. They create an imaginary audience that scrutinizes their every move. There is a presumption that others will see both their faults and their abilities in the same way that they do themselves. Believing themselves the centre of attention to so many people leads to a sense of uniqueness in the adolescent. They cannot see that others would understand their feelings, which, in their opinion, are of universal significance. Elkind calls this a personal fable, where adolescents see themselves as the centre of a drama that has little connection to reality. He describes the major task of early adolescence as the conquest of thought, where all possibilities are considered whether based in fact or not. He has applied Piaget's cognitive theory of formal operations to the behavioural dimension. The process of 'conquering thought' leads to the formation of identity as described by Erikson. Through consideration, acceptance or rejection of ideas and behaviours adolescents experiment and express their sense of identity. As their social circle widens and they increase in a variety of life experiences, adolescents gradually develop a more realistic view of their own significance and are increasingly capable of accepting the different perspectives of others.

\section{Socio-cultural context in adolescent development}

The role of the environment suggested by Elkind is explored further by Bronfenbrenner (1917-2005), psychologist and professor of Human Development, in his Ecological Systems Theory (1979), which proposes that human development is a lifelong joint function of the person and environment (Fig. 1). He places the individual in the centre of ever-expanding contextual levels. The socialisation that occurs between the adolescent and people in their immediate environment affect and is affected by larger social systems. With reciprocal interactions at all four levels, the person and environment are each in a state of flux and are able to influence each other. According to this model the individual needs to be viewed in their many 
dynamic contexts: social, historical and cultural, where both nature and nurture affect development.

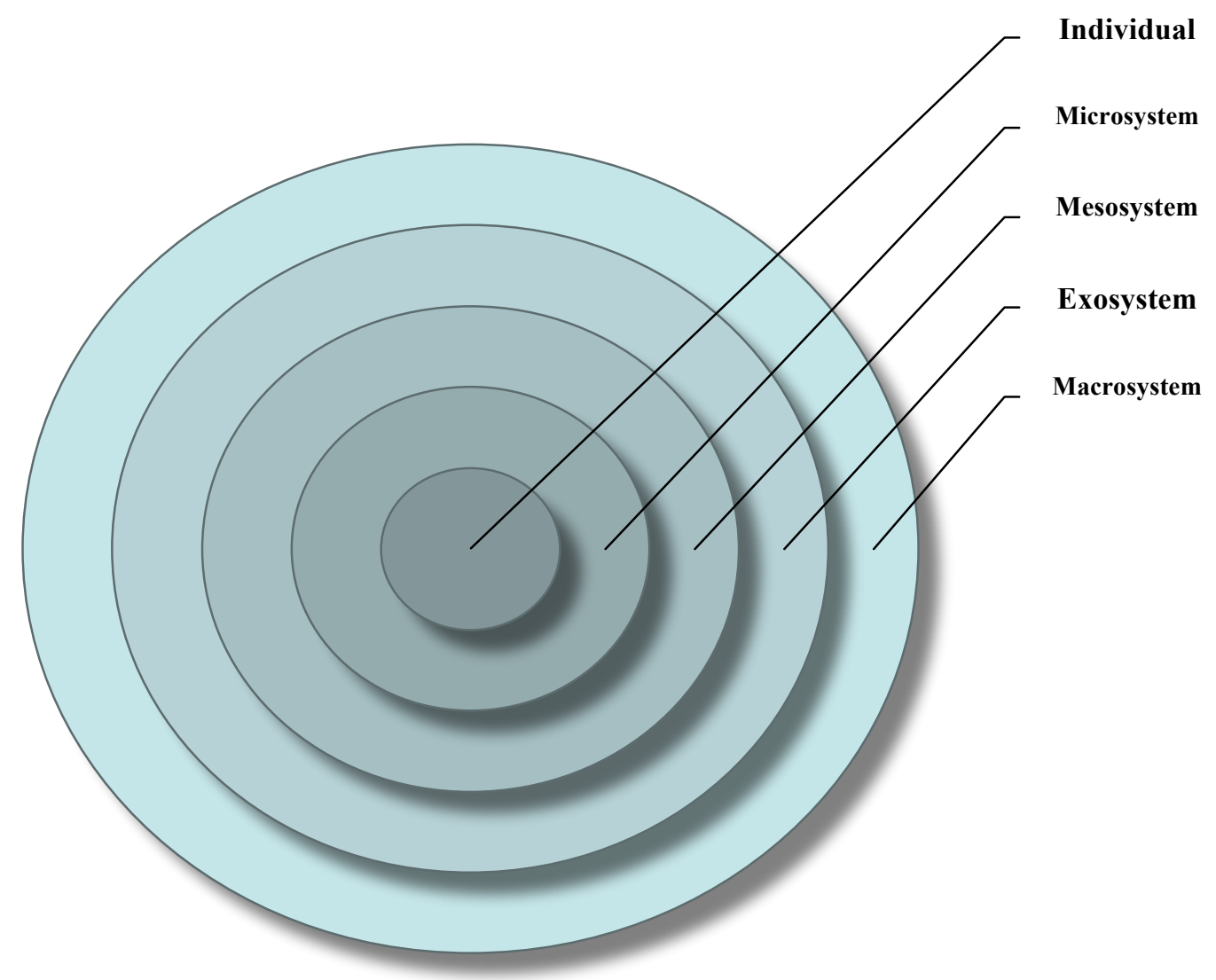

Microsystem: Innermost Level. The person's immediate environment: Home, work, school, neighbourhood and so on.

Mesosystem: Second Level. Connections among things in the microsystem.

Exosystem: Third Level. Social settings not containing the individual: Parents' workplace, mass media etc.

Macrosystem: Outermost Level. Values, customs, laws, beliefs and resources of a culture/society.

Figure 1. Model of the Environment: Schematic Diagram Showing Levels of the Environment in Bronfenbrenner's (1979) Ecological Systems Theory.

Source: www.eduction.umd.edu/Depts/EDHD/geron/lifespn/6.html. Accessed 21/11/07 
Aspects of the environment for adolescents in Western society can therefore be considered to affect their development. Adolescents are generally under pressure educationally, socially, sexually and, in some cases, financially for the first time in their lives. Some of this pressure comes from the range of alternative choices within Western democratic society. According to Erikson, (cited in Dacey and Margolis, 2006, p.192), the identity diffusion and resulting anxiety are more likely with so many choices. This highlights the impact society has on identity development. Subjectivity and variability in societal response add to the struggle to stabilize adolescents' identity. Adolescent self-image is dependent upon the individual expectations of those adults around them who make up their environment - specifically here: voice and music teachers, parents and audiences. Opportunities for social comparison intensify, so adolescents develop awareness of their strengths and weaknesses compared to others.

Gender intensification describes the increased differences in expectations between genders that occur during adolescence (Balk, 1995, p.59). The expectations are culturally and socially constructed and have little biological imperative (Unger, 1990). The harm lies in the restrictions to the behaviour, experience and future opportunities of both boys and girls.

\section{Spiritual development in adolescence}

The cognitive development that occurs during adolescence encourages growth in social reasoning (Balk, 1995, p.227). In turn this leads to questions about morality and faith. Part of the process of achieving identity is discovering and committing to the ideas and values that give our lives meaning. Spirituality is a way of connecting personal experience to our immediate physical environment and to humankind, past, present and future. Elkind (1967, p.69) links the development of spirituality with the personal fable writing "The search for privacy and the belief in personal uniqueness leads to the establishment of an I-Thou relationship with God". Developing an awareness of a personal spirituality is not necessarily connected to organized religion (Tolan, 2007), rather, through interpersonal relationships and self-reflection, adolescents develop their own belief systems. 


\section{$\underline{\text { Vocal changes in adolescence }}$}

The rapid physical growth of adolescence impacts significantly on the adolescent larynx often triggering anxiety. For boys, the vocal folds grow 4-11 mm, thereby lowering the speaking pitch of the voice by approximately one octave (Sell, 2005, p.99). The timing of this change cannot be predicted, nor the length of time until it settles into some kind of predictability of function.

Girls' voices may also lower but only by about a third of an octave. However, one of the hallmarks of the adolescent female voice is a breathy tone. As falsetto is generally initiated with a breathy onset adolescent girls are often found singing with this voice quality. Sometimes described as the 'little girl' voice, this explains why it often takes such large numbers to make girls' choirs audible. Choral singers are also prone to using falsetto excessively due to the fact that it is a less distinctive sound and more easily blended. Adolescent girls often complain of having two voices. While using speech quality for a strong sound in their lower range, the voice often flips into a soft falsetto as the pitch rises. As falsetto sound becomes more organized at higher frequencies these singers like to sing high but are wary of their middle range. Both speech quality and falsetto are produced with a vertical larynx; therefore learning to tilt the larynx is a high priority early on in their training.

Postural problems affect the voice of both boys and girls. Self-consciousness, tension and peer-pressure can influence the way in which adolescents hold themselves. Common issues are slouching posture; exacerbated, if not caused, by the development of breasts for girls. There is a tendency for the chin to jut forward, knees to lock and to a sway lower spine. Adolescents are relatively unaware of tension in the neck and jaw. Girls often hold in their abdominal muscles and resort to clavicular breathing in an attempt to keep a flat-looking stomach. ${ }^{1}$

In summary, whether describing the physical, social, spiritual or cognitive aspects of the period called 'adolescence', the overriding impression is that it is a period of

\footnotetext{
${ }^{1}$ Classical dance encourages tight abdominal muscles.
} 
uncertainty and change. Considering that vocal musical performance makes demands on the entire organism, the adolescent singer is likely to be unsure of their resources (both personal and vocal) which may in turn lead to a susceptibility to MPA. 


\section{Chapter 2: Music Performance Anxiety - What is it?}

Music performance anxiety is the negative experience of stress before, during, and/or after performance.An understanding of anxiety is not possible without first exploring stress, its purpose and effects.

\section{Stress and its purpose}

Stress is a natural part of everyday life. Canadian endocrinologist Hans Selye (19071982) defines stress as "the nonspecific response of the body to any demand made upon it" (Selye, 1980, p.27). Its purpose is to assist the body in adapting to the demand at hand and afterwards in returning the body to its normal state of functioning. Selye (1980) termed this process the general adaptation syndrome and noted that the process comprised three distinct stages : (1) the alarm reaction where the task is experienced as a hardship; (2) the organism's full adaptation where the symptoms decrease and the task becomes more bearable; and (3) a stage of exhaustion if the stressor is severe or prolonged. Interestingly, Selye discovered that the adaptive process was initiated irrespective of whether the person perceives the source of the stress as positive or negative (hence the term 'nonspecific').

Selye (1980) divides stress into four quadrants based on intensity (hypo- or hyperstress) and positivity (eustress) or negativity (distress) as shown in Fig.2. Predicting whether a demand will be perceived as challenging and exciting or debilitating is difficult as identical stressors affect individuals in varying ways. Even the person's vulnerability is considered a factor in whether a stress response occurs (Lazarus, 1999).

\section{Coping systems}

Coping systems are developed in stage 2 of the general adaptation syndrome. They can be habits/personality based or defined as a process to manage psychological stress (Lazarus, 1999, p.111). Stress levels are directly relative to the effectiveness of coping strategies (Lazarus, 1999, p.102). Lazarus cites a study on coping in adolescents by Seiffge-Krenke (1995) which revealed two functional coping styles in adolescents, which she labeled active and internal coping, and one dysfunctional style, which she 
labeled withdrawal (Lazarus, 1999, p.180). An active coping style is problemfocused, that is, the adolescent tries to change their relationship to the environment in order to alleviate the stressful situation. Internal coping is emotion-focused which means the adolescent attempts to regulate their emotional response to stressful or potentially stressful events. For the adolescent who is struggling with new experiences, environments and responsibilities in their quest for independence, stress serves as an inner warning signal to keep them safe. It warns the adolescent they need to change their behaviour in order to better manage the situation. The circumstances that provoke stress change as we move into adulthood, but its existence and role in adaptation remain (Folkman and Lazarus, 1980). Viennese psychoanalyst and child developmental psychologist Anna Freud (1895-1982) examined her father's theories with particular reference to adolescent development. She felt that some stress was necessary for adolescents to mature and develop autonomy (A. Freud, 1972). According to George Ladd (2006, p. 342), stress-provoking situations provide an opportunity for personal development as long as the individual is not overwhelmed by them.

\section{Overstress}

(hyperstress)

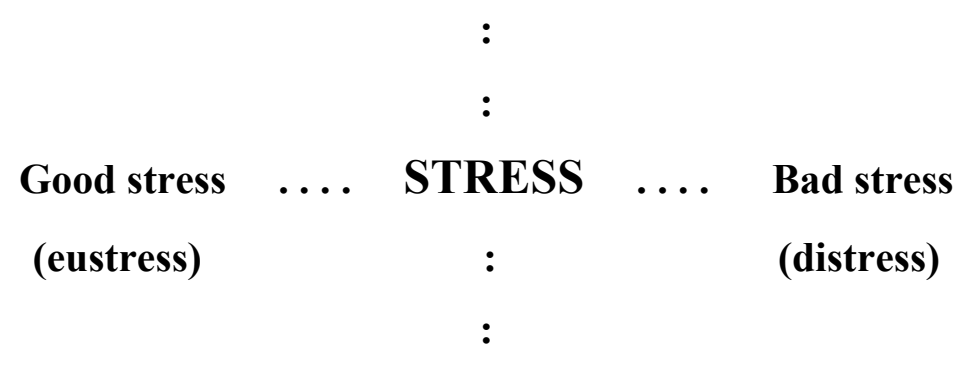

Understress

(hypostress)

Fig. 2. The Four Basic Variations of Stress (Selye, 1980, p.142) 
Kutash, an American psychologist, introduces the concept of equilibrium, the point at which the individual experiences tranquility or the optimal stress level for the adolescent singer's ability to use that stress consciously and constructively (Kutash, 1980, p.464-5). The point where equilibrium sits on the axes differs for a singer midway through a performance as compared with a less demanding activity such as watching a movie, with the latter situation reaching optimal levels sooner than the former. If, according to Kutash's definition, equilibrium, is the level of stress that can be used 'consciously and constructively' it could be surmised that equilibrium occurs during stage 2 of Selye's general adaptation syndrome and is an indicator of the adolescent singer's successful development of coping systems to handle the demand. Equilibrium could be described as the goal for which the body aims when producing stress responses.

\section{Anxiety}

Stress commonly develops into anxiety in three ways: the stress can be felt as distress (see Fig.1), the level of stress can be too high (overstress), and/or the stress may be prolonged. Note that Selye's diagram fails to accommodate this third dimension of time as it depicts types of stress rather than its complex descendant: 'anxiety'.

Anxiety is considered to be a negative learned response to a neutral stimulus. A definition of anxiety is offered by Buechler and Izard (1980) in their Differential Emotions Theory; an approach which studies the role of the fundamental emotions in "the development of adequate coping skills and exploratory, creative abilities" (1980, p.285). According to Buechler and Izard, the fundamental emotions (interest/excitement, enjoyment/joy, surprise/startle, distress/anguish, disgust/revulsion, anger/rage, shame/humiliation, fear/terror, and contempt/scorn) have no inherent positive or negative value on their own, rather their effectiveness depends on the individual-environment interactions. In this scenario, fear forms the base central emotion of an anxiety pattern which is accompanied by different combinations of other fundamental emotions, such as sadness, anger, shame, shyness, and guilt. This theoretical framework helps to explain the variable nature of the anxiety between individuals and within one individual's experience. If the pattern recurs frequently it stabilizes and becomes the likely future response under similar conditions. 


\section{$\underline{\text { Music performance anxiety }}$}

Symptoms of MPA may include cognitive, physiological and behavioural responses, in any combination and to varying degrees.

\section{Physiological symptoms of MPA}

As human beings we are not well adapted to the requirements of concert performance. The physiological symptoms of stress are what remain of the adaptations our ancestors made to the very real threats they faced to their survival. The 'freeze, flight or fight' response is designed to help us quickly assess and implement the actions that will be most effective in keeping us safe. There are four vital requirements of the body when faced with an emergency situation. Firstly, we need to think quickly in order to be able to either avoid or cope with the danger. When a person faces a life or death situation they will often describe how their entire life flashed before their eyes. Breathing and heart rate may increase (tachycardia and hyperventilation), or we may sigh or suffer from chest tightness. By becoming hypersensitive to sound, sights, and smells we can assess our situation quickly and in detail. Secondly, the body produces several responses that increase speed, such as a desire to go to the toilet or diarrhea, butterflies in the stomach and/or nausea. Muscles gathering strength in preparation for a fight may tense or spasm (Lehrer, 1978, p. 136). The muscles generally work in pairs where tension in one muscle is balanced by relaxation in the opposing muscle. But if all the muscles tense at once the result is uncoordinated or poorly controlled muscle responses (Steptoe, 1989, p.3). Agility improves by sweating from the hands or feet (diaphoresis). Thirdly, the body attempts to protect itself from damage by peripheral vasoconstriction. When we are anxious blood vessels near the surface of the body constrict in order to protect the body from cold or blood loss from trauma. The resulting symptoms are coldness and numbness in the hands and feet and paling of the skin (Lehrer, 1978, pp. 135-136). Fourthly are the symptoms which encourage us to 'freeze', such as extreme fatigue, dry mouth and dizziness. A surge of hormones is responsible for the activation of these 'fight, flight or freeze' responses. Therefore hormone secretion and body tremors may be noticeable as the hormones release from the system (Ladd, 2006, p. 344; Roland, 1997, pp.8-11). Reviewing all the symptoms described here, it is difficult to see how any could actively improve the quality or enjoyment of vocal performance. 


\section{Cognitive symptoms of MPA}

With the pressure of performance an adolescent singer's fight/freeze/flight response requires intense focus on survival options and rapid dynamic cognitive activity. The mind's focus and activity are therefore diverted from the vocal performance. Cognitive symptoms of MPA include loss of concentration, mind blanks, catastrophic negative images and distraction. From the singer's perspective, even low-level distraction can impact performance. Memory blanks are common even at the same time a performer is alert to the examiner frowning at their copy of the music. Obsessive thoughts about failure are another symptom of MPA. As students continuously visualize their own performance failure it becomes more likely that they will perform in that way (Roland, 1997, p.11).

\section{Behavioural symptoms of MPA}

The third variation of symptoms is behavioural. The increase in arousal level which prepares the singer for facing the performance brings with it undesirable tension, agitation or restlessness, instability and nervousness. Adolescent singers in particular may become negative, worry excessively and act in a panicky way. Behavioural assessment of anxiety looks at the conditional triggers and divides them into four categories. A person suffering anxiety may (1) lack needed behavioural skill; (2) lack information; (3) have been conditioned to respond with anxiety; or (4) be exposed to cognitive stressors (Suinn \& Deffenbacher, 1980, p.394). Due to the underlying fear in MPA, singers can begin to avoid the activity that initiates anxiety. Avoiding practice compounds the fear of performing, as the adolescent singer is aware they are not prepared. If a singer is overwhelmed by their fear of performing their natural response is to avoid repeating the experience and therefore their skills both in singing and in coping with (dis)stress will be limited (Roland, 1997, p.11, and Ladd, 2006, p.344). Other examples of behavioural symptoms are obsessive practicing, inability to accept compliments after performing, or even sabotaging performances by arriving late. 


\section{Chapter 3: MPA - Causes, Conditions and Triggers}

Just as the symptoms of MPA are varied, so the causes of MPA can be either external or internal. Lazarus (1999) names these variables that influence stress and emotion environmental and person variables.

\section{External triggers}

Lazarus (1999) categorizes environmental variables as demands and constraints (what society says we should and should not do), opportunity (fortunate timing and wisdom to act appropriately), and culture (groups with a common outlook may have similar stress responses and/or select similar coping strategies). Applying these concepts to MPA shows some adolescent singers feel anxious due to expectations associated with the music and their ability to perform it. Such performance expectations may be perceived as either a demand from the music or a constraint if they believe they are ill-equipped for the task. Some adolescent singers are affected by the size or significance of the audience while others are affected by the lights, their relationship with a co-performer, accompanist or conductor, or the fact they are being assessed for this performance in some way. These anxiety triggers are loaded with cultural conceptions based on the lower status of adolescent singers as compared to musical colleagues, teachers and audiences. Still others report no anxiety until they become aware of the presence of the first physiological symptoms. This may trigger further physiological and behavioural responses that disrupt their performance (Suinn \& Deffenbacher, 1980, p.393).

\section{Internal triggers}

Internal triggers are activated when environmental variables interact with person variables. These include goals and goal hierarchies (a goal needs to be at stake for stress to occur), beliefs about self and world, and personal resources (such as intelligence, money, health etc.) (Lazarus, 1999). Emmons and Thomas (1998) consider the cause of MPA to be a perceived imbalance between what is demanded of the individual and that individual's feelings regarding their capability to achieve what is being demanded. Here, it is worth bearing in mind the findings of Bronfenbrenner's Ecological Systems Theory that discuss the interactions and interrelationships 
between the individual and various levels of their environment. The triggers may be initiated at any level of the environment. Goals and goal hierarchies may be imposed on the adolescent singer by the school syllabus, for example. In its interaction with the individual the trigger derives the potency to activate anxiety. Beliefs about self and world exist in all levels of the theory. Society, their family, or most significantly, themselves may consider a successful adolescent singer precocious. The low value placed on music in a sporting culture or family is another example of the intercontextual nature of internal triggers. Adolescents are highly dependent upon the adults in their mesosystem for many personal resources, such as money, health, and educational opportunities.

Although they may behave autonomously, adolescents may not have sufficient cognitive development to put their experience of MPA into perspective. Gallwey (1976, pp.5-6) lists thirteen emotional states of mind that bring about a malfunction of the neuromuscular mechanism. Each is a factor in a singer not performing at an optimal level. Not only can the presence of these states of mind affect the body's fine motor control, but they may also develop into other types of music performance anxiety. If these emotional states are grouped according to the impact of theoretical concepts described earlier, the result is as follows:

\section{Imaginary audience}

Elkind's concept that adolescents place pressure on themselves by sensing that they are being watched continuously is a factor in the states of mind of fear and selfconsciousness. Awareness that they are being observed can inhibit students due to self-consciousness. Psychological safety lies in being 'normal' and treated the same as everyone else (Thies, 2006, p.399). This is particularly so in early adolescence (1013yrs) when peer pressure peaks. Solo musical performance is a highly conspicuous activity that involves great emotional risk. Unfortunately, feeling self-conscious means the singer is so acutely aware of the audience that they see themselves as the object, rather than the active subject of the primary act of singing. 
Kohut (1985, p.44) states that self-image can set the limits of potential. Here the adolescent's newly developed ability to think abstractly affects thoughts and beliefs about self. The imaginary audience is a tool on which adolescents 'try out' the impact they have on others. Negative self-image results in reduced capacity to learn and, by extension, to cope with the stress of performance. Self-esteem gives us the ability to adapt psychologically in everyday life, without which the stress of performance is likely to be negative and intense. Adolescents will often find it easier to condemn themselves before someone else has the opportunity to do so. Taking into account the intensity of self-focus as described by Elkind (1967), they believe others are as focused on their faults and inadequacies as they are themselves. Self-condemnation is a mechanism by which adolescents retain control of their self-image after having projected their negative self-image onto the audience.

\section{Personal fable}

The personal fable is a belief held by many adolescents that tells them that they are special, unique, and indestructible. Here the adolescent's thoughts and experiences are exaggerated in significance. 'It is the personal significance of what is happening which is the proximal cause of a stress reaction' (Lazarus, 1999, p.55). Live performance gives no second chances or opportunities to adjust an imperfect performance and performers have only a few moments to display years of training and preparation. Adolescent perfectionists have a tendency to over-prepare in order to reduce the risk of not singing well. Failing to achieve perfection in public may be cripplingly embarrassing for the adolescent perfectionist. They find performing very difficult, as they are painfully aware of the mistakes as they occur and tend to believe the audience must be too. This can even extend to a need to explain to the audience that they are aware of their mistakes: 'It was so much better at home'. Adolescents who fit this mould need to prove their worthiness to themselves and the audience. They lose sight of the bigger picture and become bogged down in the detail. For example, in their quest to 'conquer' a technical difficulty (which may be imperceptible to the majority of their audience), they will commonly sacrifice the character of the song. 
Adolescent perfectionists have unattainable and unmeasurable goals that guarantee failure in a live performance situation. With such a large portion of an adolescent singer's time spent in studio preparation where it is possible to go back and fix mistakes, the adolescent singer can be dismayed in performance at their inability to get it right first time. In competitions it is seen in the singer who often will be unable to continue after a minor mistake and needs to go back and start the performance again. This tendency is further exacerbated by the proliferation of studio recordings that give a false sense of reality to a singer.

As they gradually develop from concrete to formal operations thinking, adolescents may still tend to see performance as a simple input/output equation. In other words the more effort they put in the better the results (and external positive reactions) should be. 'It's not fair; I practiced for ages. The harder I try, the worse it gets' (female student, aged 14). ${ }^{2}$ This student is not aware of the many other factors at work in determining the performance quality. More effort both in physical terms and in terms of practice time does not guarantee results. The singer may feel betrayed when their effort does not produce a positive result and when they see others achieving better results with less work. Increased effort levels interfere with the creative, expressive brain function required for music making. Kohut $(1985$, p.7) describes the natural learning process of young humans as progressing from mental imagery, through imitation, followed by trial-and-error practice. Verbal cognition (the development of language) interferes with the natural learning process. We are taught to learn with intense mental and physical effort rather than the perceptual-motor learning used by children. The learning process is further complicated by a reduced awareness of body feedback. By not prioritizing body and sensation awareness during practice adolescent singers are more likely to interpret the symptoms associated with MPA negatively in a performance situation. The adolescent singer starts to argue with their results mid-way through the song as their voice behaves differently under the strain of MPA. The cognitive development that appears in later adolescence enables them to start taking contextual factors into account and to share control with the environment (Thies, 2006, p.402).

\footnotetext{
${ }^{2}$ Quote from a student in the author's private teaching studio.
} 
As well as their own expectations of personal achievement, the expectations of others can be a cause of negative stress. If significant people such as family or teachers place pressure on the adolescent singer to succeed they may feel overwhelmed. More external pressure may correspondingly raise their level of potential guilt if the performance falls below expectations. Age-related goals and comparisons with other students may increase MPA if their level of achievement falls below standards expected.

Another aspect of perfectionism is jury consciousness, the awareness of being judged. The personal fable, which asserts the uniqueness of the adolescent's experience, deceives the adolescent singer into framing the jury as an enemy who couldn't possibly understand how it feels to be assessed on their performance. It is a sad fact that social singing has rapidly declined in our society. Today's adolescent singer has so few forums in which to perform. The currently accepted route involves grade examinations, school music, competitions, followed by a university degree, then auditions for further study or roles. Even an active career involves constant auditions and performance reviews. Being judged constantly on what, for some, is a form of self-expression can therefore be particularly difficult at this age. Perhaps this explains the great shift to contemporary music where young people express themselves without any need for adult approval. Erikson (1950) described the adolescent's drive as a need to define themselves rather than be defined by the older generation. School and examination syllabi struggle to include contemporary forms in their programmes. But it may be the need to escape the jury system itself rather than the appeal of contemporary music that drives some adolescents to extend the boundaries of style.

It seems unfair that doing well can also cause music performance anxiety. When an adolescent singer has experienced some success, in whatever form, the stakes go up for subsequent performances and the added attention may make them uncomfortable. If they feel undeserving of the success they may be overwhelmed by insecurity. Belief in personal uniqueness may make the adolescent feel that others have made a mistake in giving them success. The result is variously called 'success conflict' or 'success syndrome'. It is harder to focus on the task of singing when there is the risk of disappointing the raised expectations of others. Adults may inadvertently trigger negative stress in the adolescent singer even while intending to reinforce the 
adolescent singer's positive self-image and provide encouragement. The pressure to continue succeeding can be such that anxiety sabotages their singing. Self-doubt is increased by Tall-Poppy syndrome: it is emotionally safer to be striving upwards than waiting to be knocked off your pedestal. In her book The Inner Voice, Renee Fleming (2004, pp. 108-109) describes her near breakdown and experience of stage fright as being unused to success: “As a woman, in particular, I feel I wasn't socialized for success. Number two, the first runner-up, gazing adoringly at the winner, had always been my favourite role."

Positive reinforcement can often be age-related. Success in early adolescence is often based on pure talent that stirs far less external excitement once the singer reaches their early twenties. A singer in late adolescence may be distressed to find that they no longer receive the support and accolades they did in early adolescence. Despite increasing their efforts as they get older, adolescent singers may sense an increasing distance between how others see them and how they see themselves as special and unique. The apparent decline in success may be overwhelming as they face challenges without the support and guidance of adults that they received when younger.

Internally, a string of successes can initiate an increase in levels of aspiration that exceed a singer's capability. Despite their success, the singer still experiences the anxiety caused by the gap between their current ability and their expectations. Important future goals that are not broken down into small, achievable and measurable tasks become oppressive rather than inspiring.

\section{$\underline{\text { Identity diffusion }}$}

Certain emotional states are the result of failing to develop adequate coping systems and subsequently being overwhelmed by the stress of performance. Erikson (1950) theorized that failing to resolve a crisis in the transition from one psychosocial stage to the next results in a state called identity diffusion. Without a healthy, secure sense of identity a person may react to stressors in negative ways. Perhaps identity diffusion is the underlying factor in the rate at which adolescents discontinue their vocal training. By rebelling, the adolescent singer directs their focus outwards at those whom the adolescent deems to be causing anxiety. Anger and frustration are included 
in Gallwey's list of emotional states that have a negative impact on the neuromuscular mechanism (Gallwey, 1976). Such emotions may appear when an adolescent singer, without a secure sense of identity, is unable to recognize their personal input and responsibility in their experience of MPA. At the other extreme, an adolescent singer may feel frustration that internalizes the response with feelings of shyness, embarrassment, shame and guilt (Izard, 1972, p.76). Identity diffusion results in an imbalanced perception of the dual responsibilities of individuals and their various environmental contexts.

Lacking the will to succeed is one way to avoid the pressure of the imaginary audience and the personal fable. Opting out of the competitive nature of performance may mean that the adolescent singer's body, mind and behaviour are not primed to run at the optimum level. For some this lack may be caused by success conflict. Other adolescent singers are so afraid of failing in competitive situations that their fear prevents them from wholeheartedly attempting to sing successfully. Balk (1995) points out that girls are generally less competitive than boys. Boredom is also a factor in stress levels being too low. Over time, lower levels of achievement associated with boredom may cause dissatisfaction leading to anxiety. When interest levels are low it is easier to suffer from poor concentration. In turn, this may increase off-task mental activity such as worrying that their learning and motivation should be progressing in a linear direction. They may also blame their teachers for their lack of motivation. Russian psychologist Lev Vygotsky (1896-1934) proposed that development is like a tidal wave: it has both forward and backward motion but is ultimately progressive (Wink/Putney, 2002, p.89). Learning to take the many factors of their existence into account may help the adolescent to understand that their current state of apparent indifference is still part of their development as a performer and a person. Boredom tends to signify a need for change and it may be that the smallest thing, even the acknowledgement of its existence, is enough to initiate the next big wave of forward development.

In summary, stressors may be either environmental triggers or internal emotional states. MPA is caused by the impact of the stressor on the adolescent singer and the adolescent singer's response to that stressor. This exchange will affect their cognitive, emotional and physiological functioning. 


\section{Chapter 4: Solutions and Treatment of MPA}

Although the 'flight, fight or freeze' response has a role to play when managing external threat, anxiety that is caused by internal factors engenders the same symptoms and is still manageable (Emmons and Thomas, 1998).

In his socio-cultural approach to human development, Vygotsky (1978) proposed that learners could develop beyond their independent capabilities if offered guidance and support from a more knowledgeable 'other'. He termed the support 'scaffolding' and defined its role as facilitating the learner's ability by building on prior knowledge and internalizing new information. Vygotsky maintained that it was important that scaffolding provided activities just beyond the level of what the learner was able to do alone: should the activities be too advanced or demanding, the learner would not manage the task. Vygotsky coined this critical space the 'zone of proximal development'. For the adolescent singer experiencing MPA, this theory is important for two reasons: first, it recognizes learning as an "interrelated, dynamic process" (Wink \& Putney, 2002, p.86) and second, it underpins the central role of the 'more knowledgeable' voice teacher and his/her attitudes and actions.

Treating adolescent singers with MPA begins with an assessment of what variables are causing the response, what triggers the response, and which symptoms the student is experiencing. Careful assessment means that treatment can be targeted effectively to each student. Appendix 1 provides a useful questionnaire developed by Emmons and Thomas (1998) to help singers assess their personal approach to vocal performance. Typically, students need help to identify the negative thought patterns, physical symptoms and behaviours that MPA triggers in them. Being actively involved in the task of problem-solving gives the adolescent singer a much-needed sense of control that may have been damaged by MPA.

Buechler and Izard's differential emotions theory (1980) proposes that two fundamental emotions, joy and interest, are mutually exclusive of the experience of fear. Viewed in the context of Selye's four variations of stress (Fig.2) we may 
hypothesize that in order to turn MPA distress into eustress the fundamental emotion fear must be replaced by joy and interest. Adolescent singers will have an infinite number of triggers for the distress of MPA including internal negative thought patterns and environmental factors. The process of identifying these triggers can be replicated in the process of systematically identifying what causes them to experience joy and interest.

Central to any change is the adolescent singer's capacity to visualize clearly their state of equilibrium (optimal stress) in performance and to affirm that this state is attainable. Here, teacher guidance and encouragement are vital. Emmons and Thomas (1980, p.150) describe this state of equilibrium as an 'ideal zone of arousal', a phrase which may resonate more easily with the adolescent singer's psyche. Within this zone, the adolescent singer's goals, beliefs and personal resources (person variables) have been shown to be able to manage the immediate demands, constraints and opportunities (environment variables). Should cognitive or somatic anxiety be too high (or low) however, the adolescent singer will move from a state of readiness to a state of instability. Singing requires fine motor control; consequently singers are less able to cope with high states of arousal in performance as compared to a rugby player, for instance. The quality of the adolescent singer's performance will deteriorate quickly once outside the ideal zone of arousal. Appendix 1, as mentioned above, offers a set of self-awareness exercises which may be used to help the adolescent singer uncover their own patterns and symptoms of MPA that take them outside the ideal zone of arousal.

Greene (2001) describes various methods for controlling performance energy. Developing the ability to focus, which he calls centering, is the first step (Appendix 2). Being 'centred' means the body and mind are working together in a state suited to optimal performance. Overthinking and tight muscles are released in the process. Kohut (1985, p.8) describes our society and western traditional teaching methods as visual, scientific, verbal and cognitive. On the other hand, musical performance is an aural, aesthetic, non-verbal, and perceptual-motor skill. 
"Mind-body integration ... involves the mind and body working together as an integrated unit to achieve a specific motoric goal. This is achieved through developing one's powers of concentration to a very high level. Orientals do it through practice of various meditation exercises. The most basic one involves focusing on one's own breathing." (Kohut, 1985, p.57).

Examples of breathing exercises are outlined in Appendix 3 and a method of somatic relaxation in Appendix 4.

Once the ability to become centred is established, the adolescent singer can increase the amount of pressure on himself or herself while still functioning at optimal level. For example, practicing singing after exercising for several minutes. The student uses the centering process to reduce the heart rate and to manage physiological arousal while singing. Visualizing an audition panel while practicing a complete performance, managing an entire programme without stopping, and performing to a tape recorder are all examples of methods to encourage adaptation to higher levels of performance pressure. If the usual conditioned response to these triggers is anxiety, then centering becomes an effective method to manage the arousal level.

Greene (2001) then uses process cues to develop the ability to focus on the activity at hand. Process cues are words that describe the individual's best singing or what needs to be done to achieve it. They vary over time and from song to song. If the process cue resonates with the student, it draws the focus away from negative self-statements that cause anxiety.

Once the types of negative self-talk are identified, another effective technique is to externalize these by giving them a name. Negative personal statements are compelling and self-defining. Externalizing those negative statements makes it easier to challenge them and replace them with positive ones that enhance our self-image. Positive selftalk should be rehearsed in all four stages of performance, namely during preparation, before, during and after the performance (Roland, 1997, pp.18-21). The statements should be realistic, for example, "I'm bound to make a few mistakes but so does everyone", and "the audience wants me to sing well and will make allowances for any slips". Such statements are more likely to be made by those who experience moderate 
levels of MPA (as opposed to very low or very high). Steptoe (1989, p10), like Roland and Greene, recommends preparation and practice in positive task-orientated self-statements.

\section{Behaviour Therapy}

Treating anxiety with behavioural therapy assumes that we can alter anxiety patterns through relearning, and that we can either learn to eliminate the anxiety or acquire sufficient coping skills to manage it. In behavioural therapy, the precise cause of the anxiety is not focused on, but rather the adaptation required in order to return the body to normal functioning. Behavioural therapy requires concrete goals that pertain to the present rather than rekindle past failures. New adaptive behaviours that intervene in the habitual patterns of anxiety response are put into practice. Suinn and Deffenbacher (1980) cite several studies that suggest this process can be achieved vicariously.

\section{Desensitization}

Desensitization pairs the situation causing anxiety with relaxation responses. The process of desensitization aims to weaken the connection between stimulus and response. This is achieved by attaching new responses to the original stimuli. There are three stages to the process: (1) guided relaxation exercises are practiced. These may include deep muscle relaxation (Jacobsen, 1974), hypnosis, autogenic training, drugs, breathing exercises, biofeedback or meditation (Suinn \& Deffenbacher, 1980, p.396). (2) A hierarchy of anxiety-producing situations is constructed. Here the voice teacher and adolescent singer can work together. The student's lists may include such diverse things as choosing repertoire, listening to other singers, memorizing a song, auditioning for a school production, or singing in an examination. The student then ranks the experiences in order of fearfulness. The idea is to structure a journey that begins with the most achievable situation. (3) The adolescent singer then practices their relaxation techniques while clearly visualizing the scene. For desensitization to work, it is vital that the relaxation techniques are practiced effectively. The sense of relaxation must be associated with the scene more strongly than the habitual anxiety response. Once the student achieves full relaxation while clearly visualizing the scene they are ready to move on to the next one on the list. 
The singing teacher's list may include graded performance opportunities, moving from asking the adolescent singer to sing for family members, through to performing in a major concert or even on the world stage. At all times the singing teacher must ensure that the performance opportunity will extend rather than overwhelm the student. The adolescent singer's ability to cope is developed systematically as they manage increasingly stressful performances. Thus Vygotsky's concepts of the zone of proximal development and scaffolding are satisfied.

\section{Anxiety Management Training}

Similar in concept to desensitization, Anxiety Management Training (AMT) as described by Suinn \& Deffenbacher (1980) targets the anxiety responses rather than the trigger situations. In applying AMT, adolescent singers are asked to visualize anxiety-triggering scenes and then analyze these to determine which anxiety responses are provoked. Common anxiety responses are cold limbs or shallow breathing as soon as they think about an upcoming performance. They then train themselves to respond with relaxation techniques as soon as these cue symptoms appear.

AMT comprises five phases. Phase 1 assesses the adolescent singer's anxious behaviour in order to obtain a detailed description of a scene that the student experiences as stressful. Deep muscular relaxation technique is taught and then practised independently (see Appendix 4). In phase 2 the adolescent singer is guided through a visualization of a relaxation scene that is then followed by the anxietyprovoking scene. In phase 3 the therapist alternates the scenes, helping the singer to experience both the anxiety then the process whereby using the relaxation techniques reduces the rate of arousal. In phase 4 the adolescent singer is given more control and independently chooses when to apply relaxation techniques. In the final phase, the techniques are transferred to real life situations.

This approach has several advantages over desensitization. It gives a thorough sense of control to the student and because it is not specific to a particular situation, AMT means the singer is able to reduce tension levels even if they occur unexpectedly during performance. Its use can also be of benefit in other areas in their life where they may experience anxiety; which gives more opportunity to practice the relaxation 
techniques. Those students who find that the cognitive or somatic symptoms of anxiety tend to quickly spiral out of control will find AMT intervenes effectively to return them within their ideal zone of arousal.

\section{Modeling Approaches to Anxiety Reduction}

Modeling is possibly even more effective than the two methods described above (Suinn \& Deffenbacher, 1980, pp.402-406). A student suffering from MPA would be asked to observe a model engage in the activity that provokes anxiety. Modeling situations would start at the bottom of their hierarchy of stressful situations and gradually increase the intensity. The student can observe the calm behaviour and successful result of the model's activity. The approach can be paired with guided participation, where the adolescent experiencing anxiety is encouraged to imitate the actions of the model.

The appropriateness of the application of this method within the vocal studio environment is clear. Situations can be manipulated by the teacher to suit the individual student. After choosing a suitable model a joint lesson could be arranged for example, followed by a lesson with a small audience; a masterclass; and perhaps a concert. Step-by-step the student can watch the model approach singing and performing with confidence, and be encouraged to participate.

The most obvious complication with the method is the challenge of finding a model with whom the student can identify. Vocal development should probably be equivalent, so that technical vocal insecurity does not become the primary focus. The issue of suitable pairing of model to student is avoided by another strand of the modeling approach called covert modeling (Suinn \& Deffenbacher, 1980, p.405). This variant allows students to imagine the modeling sequences rather than experience them in real life. Imagining the scenes may be more manageable, but perhaps require increased confidence on the part of the teacher. Secondly, unlike treating phobias of snakes, overcoming MPA may become an enjoyable and social activity if the dynamic between teacher, model and student works well. According to Suinn \& Deffenbacher (1980), the process may be more effective if the model is not perfect but what they describe as a 'coping model', a singer who has previously suffered from MPA but learned to manage it. Such a model can explain their own process and feelings more 
clearly and share both empathy and hope with the student they are assisting. The same concept could be extended to teachers. Experience performing both with and without MPA is likely to be advantageous when teaching adolescent singers who are experiencing it. Those who have learned techniques for self-assessment and treatment of their own performance anxiety may have developed their personal resources and expertise when assisting their students.

\section{Cognitive-Behavioural Approaches}

The central principle of a cognitive-behavioural approach to treating anxiety is the importance of our thoughts in both creating and maintaining the anxiety patterns. The stressor (in this case vocal performance) ignites cognitions that then set the singer on the path to MPA with its associated symptoms and behaviours. The disruption is out of proportion to the actual situation due to absolutist and catastrophic thinking (Suinn \& Deffenbacher, 1980).

The goal is to change the thoughts and replace them with more rational and realistic thought patterns. The effect is a reduction in arousal levels, defensive avoidance, and disrupted performance. Once arousal is in a more manageable zone the singer is capable of employing and developing their coping systems.

Two significant variants of cognitive-behaviour therapy are rational-emotive therapy and stress inoculation. The first method focuses on the irrationality of the thoughts that cause anxiety. The thoughts, once identified, are negated actively with replacement cognitions which are designed to limit anxiety arousal. Stress inoculation, on the other hand, replaces negative self-statements with task-oriented instructions. The conscious brain is too busy carrying out the tasks to sink into the habitually unhelpful thought patterns. The process of stress inoculation is structured in three phases:

1. Educational phase: Here students learn about anxiety; its cognitive and somatic manifestations. They learn the part their thoughts play in taking them over the level of arousal that engenders optimal performance. The emphasis is on self-analysis and self-treatment, which puts the student in control of the treatment. The process is clearly laid out to the student in this first stage. 
2. Skills training stage: Next the students learn stress reduction techniques. They learn to identify negative cognitions and replace them with self-instructions. They also learn applied relaxation skills in this phase.

3. Application phase: Now the skills and cognitions are practiced in visualized stressful situations. Here, adolescent singers can put their new task-oriented selfinstructions and applied relaxation techniques to the test while imagining a situation that would normally provoke anxiety. The phase can be broken down further into four stages: (1) preparing for a stressor, (2) confronting a stressor, (3) confronting the feeling of being overwhelmed, and (4) applying coping skills (Suinn \& Deffenbacher, 1980, p.408). Once the skills have been practiced in the imagination, they can be tried in real life situations.

\section{$\underline{\text { Medication }}$}

As adolescents have not always had time or opportunity to develop stress coping skills, it would seem counter-productive for them to use beta-blockers, even in extreme cases of MPA. Beta-blockers block the actions of the part of the sympathetic nervous system that mediates the fight or flight response. Steptoe $(1989$, p.4) argues that the symptoms of MPA are not specifically caused by stage fright but by the increased physiological and cognitive activation needed in musical performance. He cites studies, which prove that musicians who didn't report experiencing stage fright experience the same increased heart rates while performing. This implies that the use of beta-blockers to reduce the physical response to fear will have an impact on the resulting performance. His theory is supported by Avram Goldstein at the Addiction Research Center in Stanford, California, who found that injections of naloxone, an opiate blocker, disrupted the heightened sensation of listening to music. It was concluded that the exhilaration produced by listening to certain music was the result of endorphin release by the pituitary gland; the upshot of electrical activity spreading in a region of the brain connected to both the limbic and autonomic control centers. The use of drugs to manage MPA will not help the student to gain control over their own responses to stress or ever experience the mind/music/body integration described by Gallwey. Officially, the U.S. Food and Drug Administration do not approve betablockers for anxiolytic use. (Schneier, 2006). 


\section{The Prevention of MPA}

MPA should not be taught. Students who do not perceive themselves as experiencing MPA should not be expecting its occurrence. Suinn \& Deffenbacher (1980, p.405) caution against using coping models for teaching those who do not suffer anxiety. Their use is suggestive and not therefore conducive to the prevention of MPA. Mastery models are calm and in control from the outset and therefore preferable to use as a preventative tool.

It is impossible to guarantee prevention of MPA due to the many factors involved with its onset. What is possible is to provide a rounded set of skills training. Familiarising students with the behavioural and cognitive skills required for performing, in much the same way as for top competitive athletes, will help singers avoid the sense of helplessness that often precedes the onset of MPA. The skill sets required to perform as a singer cannot be completely provided by a single teacher. Specialist training in such areas as body awareness (such as yoga or Alexander Technique), acting skills, audience management, working with the accompanist, personal grooming, to name a few, may need outside input. An holistic approach to singing training is helpful. Teachers who have assessed their own strengths and weaknesses can look to provide balanced performance training for their students who will subsequently have more personal resources to cope with the stress of performance. Obviously performance skills cannot be taught overnight and, due to any number of reasons, the adolescent may yet encounter MPA.

Self-esteem is the most important resource for the prevention of MPA. The power of positive visualization is the key to the development of a positive self-image. Human behaviour changes according to how successfully positive self-image is incorporated into the belief system. An adolescent's underlying attitudes about self and potential will affect their performance experience. Kohut $(1985$, p.47) suggests three steps in the process of improving self-esteem: to believe a change of attitude is possible, to act upon the belief, and to practice over time and with patience. 
Philosopher and psychologist William James (1890/1950) devised this formula for self-esteem.

Self-esteem $=\frac{\text { Success }}{\text { Pretensions }}$

James explains that good self-esteem rates our abilities and accomplishments highly compared to what is possible or expected of us. It is a simple but effective equation. Infinite variations are possible. Raised self-esteem can be achieved either by increasing success or decreasing pretensions (expectations and aspirations). Obviously it is easier to control pretensions than to control the level of concrete success. In today's technological and global community, it is perhaps harder to have realistic aspirations than it was in days gone by. Instant fame and success are applauded and emphasized in the media. It is challenging for an adolescent surrounded by these values of image prominence to be satisfied with the slow, stepby-step process of vocal training. 


\section{Discussion}

\section{What constitutes a performance without MPA?}

Through the medium of the music a connection is set up between the poet, composer, singer, accompanist and audience. The communication is dynamic: it responds and adapts to the changing state of all parties involved in the performance. Due to the multiplicity of factors in live performance no two performances are ever the same. Perception of a performance is singular to each individual who performs or participates in the audience and therefore the concept of perfection is irrelevant to live musical performance. It is as if by sharing a concentrated focus with the audience a unique and unrepeatable work of art is created. There is no sense of inadequacy or of having to 'submit' to the wishes of the composer. In the process of creating the performance the singer becomes one with the work. These are the performances where time stands still and which cannot be described later. In sport psychology it is called' getting into the Zone' or 'flow'. Training and preparation are maximized once in this mental state. Responses are heightened and there is a sense of ease in singing. Something seemingly magical happens when all conscious control is relinquished. Adolescents may find releasing this control particularly difficult as they are struggling to gain control of themselves in other areas in their life.

Performing with 'flow' requires the type of stress to be eustress rather than distress. To make this positive change requires an adjustment in the environmental and/or person variables. Stress that is challenging and exciting rather than threatening is likely to be based on a foundation of the fundamental emotions of joy and interest. Gallwey (1976) focuses on interest (which he calls 'attention') in his description of the four stages that culminate in 'relaxed concentration'. Each stage depicts an intensification of the level of attention paid to the activity of performing; highlighting the role played by interest in performing without MPA. Gallwey describes the final stage as playing (for which we can read singing) "out of your mind". The phrase probably indicates a relinquishing of conscious control. What is not clear is exactly how the shift is made from stage three: absorbed attention to stage four: merging with experience. 
Studies discussed by Buechler and Izard (1980, p. 292) look at the experience and expression of fear. It is interesting to note that two factors were most effective in mitigating an infant's experience of fear: having a strong parental attachment and a sense of interest. It seems that the security of having a parent nearby gives an infant such security that they don't experience fear so strongly. Although physical proximity to their parents would not be so necessary for the adolescent singer it could be speculated the emotional and practical support of parents could have a very real and positive effect on the adolescent's experience of MPA. Adolescent singers' attitudes to vocal performance may be learned from their parents. Parents can equip their child with William James' formula for self-esteem and aim to keep the ratio of success to expectations high. A parent who insists on giving technical criticism will find the interaction tainted by the emotional requirements of the parent-child relationship. Any performance advice from a parent is likely to be interpreted as an attack on the ego but parents can reassure the adolescent singer that their self-worth is not at stake with a performance. Effective communication between teacher and parents may clarify how they can best support the student.

The second major factor was the sense of interest. Interest and fear are mutually exclusive experiences as one makes further and deeper exploration of a task desirable and the other motivates us to avoid the activity or situation. Music increases in significance during adolescence as it becomes a means of expressing the adolescent singer's tastes independently of their parents. For this reason the adolescent singer may prefer contemporary music and not consider voice training necessary. Often the drive to have singing lessons is initiated by the parents who have a longer and wider view of the value of voice training for their child. In such cases, some initial resistance to the long-term process of voice training is therefore common. Teachers need to adapt their approach if motivation is to be maintained. By appealing to the student's newly developed ability to reason abstractly, it may be possible to encourage the unappealing genres as 'exercises' or 'experiments'. Adolescents often enjoy the opportunity to negotiate a deal: for example, alternating their own song choices or compositions with those the teacher favours for musical and vocal development. Providing a safe and socially acceptable environment for 
experimentation may also benefit the adolescent singer's formation of identity. Donning the personae of various characters in song and opera may help them see other perspectives, explore different emotions and identities without it having an impact on other spheres of their existence.

\section{Are singers particularly vulnerable to MPA?}

To sing is to share a part of our humanity and ourselves. There are a number of conditions that are specific to singers that may be perceived as significant stressors. Firstly the instrument is physical and as such each is unique and continuously changing. On the negative side, they become limited by both health and age. The option of upgrading to a better instrument does not exist for singers. A singer who does not love their vocal timbre has no alternatives. Audiences have strong opinions about their preferred voices too. Fortunately they do not all agree on what constitutes a pleasing voice. The variety in taste for voices is due to social, cultural, and even biological reasons. According to Alfred Tomatis (1988) the shape of the ear canal affects our perception of whether a voice is pleasing or not. He proposes this as a factor in the differences in national tastes such as that between the Italian and Germanic styles of singing. This goes to show that responses to singing are subjective and in many ways well beyond the singer's control.

The physical nature of the vocal instrument can make receiving criticism difficult. Adolescents are particularly vulnerable due to the very rapid physical changes during puberty and criticism of the voice can be perceived as a personal attack in some circumstances. Because our body is our instrument it is a more complex task to differentiate our self-image from our perception of success or failure in performance and self-esteem is put on the line with each performance (Kohut, 1985, p.8). The ego awareness of good/bad; success/failure concepts increase muscle tension. After a very challenging session an adolescent singer cannot put their instrument away and they are forced to continue to use their voice in day-to-day exchange. Separating the voice from personal identity and self-worth requires a complex cognitive process that may not necessarily occur automatically with development. 
When a student begins to train they are brought into a teaching environment unlike most that they will have so far encountered. Due to the invisible and unique nature of the instrument they have to interpret teacher instructions for themselves in order to develop a voice of which they may not yet have a clear conception. Technical terms still often differ from teacher to teacher and there is a dizzying array of voice types, or fachs, that allow teachers to disagree about the necessary course of action for any student singer. Once a fach has been settled on, or for those whose teachers don't use the fach system, repertoire that suits the voice chosen, there is the issue of whether the student likes the sound required for that repertoire. Often roles in opera are cast with particular voice types. If a student is not the right age or personality for that 'type' the result is internal conflict. Lack of identification with the character of their voice could cause resentment and anxiety. Singers may also have problems if they don't look the way their voice type is generally cast. In this media-dominated era the quality of sound and musicianship is not enough to satisfy the audience. The pressure is particularly relevant in opera and musical theatre where the acting ability and physical suitability are considered vital.

Compared to instrumentalists singers generally start their training later. They may be less accomplished than their peers at school in technical ability, musicianship and theory. Singers are also expected to have very high standards of presentation and audience connection compared to instrumentalists. Concert etiquette suggests they perform without music and have to manage the extra dynamic of languages, whether foreign or their own.

Males have the added challenge of using a voice that changes function or 'breaks' at some point during puberty. Previously, they may feel anxiety because they are uncertain what their voice will sound like in the future. Boys whose voices have not yet lowered are often very difficult to satisfy musically. They would like to sing as a man but vocally they are not yet capable. Boys will often try to force their voices down and express fear of 'singing like a girl'. The time a voice takes to settle is variable and would certainly be a cause for distress in some males. Afterwards, males are singing with a voice that they have begun to use some 12-14 years later than their female peers. 
Finding appropriate music for adolescents is a minefield for a teacher. Vocal development and ability are generally lagging far behind their social development. Music that satisfies them socially that is also appropriate to their early vocal development is difficult to find. As a teacher it is also necessary to familiarize yourself with the home environment, as music choices generally have to satisfy the parents too. While a student may want to sing Red Hot Chili Peppers, their parents want 'I Whistle a Happy Tune'. As discussed in chapter 4, interest counters fear, therefore if an adolescent singer cannot feel a personal connection with the music they are more likely to experience anxiety in performance. The ability to create an atmosphere of relaxed concentration in performance will be hampered if they are selfconscious about the song they are singing.

With such prolific access to recorded music, adolescent singers expect to be able to produce a sound equivalent to the fully mature, trained voices they hear in their $i$ pods. With the decline of social singing young people don't hear other emergent singers in live performance anywhere near as much as singers at the peak of their career with electronic enhancement. Although such proliferation makes for a clear aural conception it may cause frustration that they are unable to recreate that sound themselves.

\section{Voice Teachers and Adolescent Singers' MPA}

The primary role of a singing teacher is to teach singing. A singer who is suffering from vocal technical difficulties generally suffers a spiraling loss of confidence and increased MPA. Tackling the vocal technique will often be enough for a singer to regain their sense of control while performing. Moreover, a teacher who is themselves interested in their subject can inspire a sense of interest in the student.

Besides the responsibility of teaching singing, teachers need to teach the art of efficient practice and performance skills. Adolescent singers should not be expected to know instinctively how to practice daily, what to wear for a concert or even how to tape their accompanist's music. There is a great deal of practical advice and knowledge that needs to be shared freely with students. Organizational support given 
to students will reduce the likelihood of anxiety being triggered. Even expecting students to keep their music neatly filed and to ensure they have an up-to-date repertoire list will help them to feel more in control. Methods for dealing with MPA do not guarantee successful performance ability. Rather it allows the arousal level to reduce enough for the adolescent to learn and employ their coping mechanisms. Such mechanisms include eye contact with the audience, physical grounding, aural connection with the accompanist, and communicating the story and/or character. Not extending these abilities may mean the student relapses into a state of MPA at a future date.

Introducing a range of appropriate repertoire choices is a vital skill for teachers. It is not only vocal and musical developments that need to be considered. An adolescent's developing identity is often expressed through the music they choose to sing and attitude bias towards certain genres can be very strong at this stage. Judgement and flexibility are required at all times to ensure that students feel they have some say in their song choices. The student may feel uncertainty about the expectations of the genre or language due to their unfamiliarity with it. They may also have increased self-consciousness when performing for their peers. Teachers are important in encouraging experimentation and also assessing the value of the student's own song choices. Balancing a range of developmental goals against continuing awareness of the level of stress being placed on the student is the teacher's brief.

Voice teachers must become familiar with the different problems students of each gender may encounter. Many boys seem unaware that the music they listen to and want to sing is impossible until after vocal maturation. The guidance and understanding of a teacher through this time of vocal maturation is likely to make the experience of 'losing' the voice which they are accustomed to a less stressful experience. Becoming excited about their developing voice and interested in the process of its change will alter the perception of helplessness they may be feeling. As newly developed male voices have less control and flexibility a teacher can make sure appropriate repertoire is attempted. Boys may also find it difficult to express themselves in performance and often are most comfortable singing with an aggressive quality. They may use too much air pressure and produce a sound close to shouting. 
Swollen vocal folds may quickly result, especially in the school rock band environment where they are competing with amplified instruments.

Adolescents have an increasing awareness of kinesthetic feedback and tend to rely less on visual information. The improvement in proprioceptive functioning is vital to the learning process. A teacher cannot perform the minute physical manipulations required to improve a student's technique. Only a singer can sense correct technique and recreate it for him or herself. As kinesthetic awareness is developing, voice teachers are often the first to help them objectively analyze the effectiveness of their stance. While adult students can commonly list their tensions, having had more time to become aware of them and seek treatment, adolescent singers often have not had the time for the accumulation of bad posture to develop into pain. This also applies to young singers who have been trained in classical dance. Self-consciousness and tension also affect the ability of adolescent singers, particularly girls, to release their abdominal muscles. Years of training can make these students resistant to abdominal release. Girls may be very uncomfortable releasing their jaws or making any type of noise that isn't pretty. Any new activity will increase stress levels and teachers are responsible for providing a safe environment in which the adolescent can try new methods without undue emotional or physical risk. In the early stages of training, attention is paid to anatomy in a new way, so that the familiar voice becomes a complex organ. Significant variation in sound quality is evident until technique becomes established. Expectations of compliments from a teacher are often overshadowed by the growing awareness that even the most 'beautiful' voice needs consistent long-term work.

Piaget's theory, which outlines the onset during adolescence of the ability to perform formal operations, is another factor in prioritizing this group. Due to the invisible nature of the vocal instrument, a student needs the ability to conceptualize their vocal function in abstract terms. Because they have not yet heard their own voice in its trained form they need to assess what effect certain factors may have on a theoretical outcome. The development of metacognition also allows adolescents to analyze their own thought processes to develop and assess their own learning. This is the strongest argument for delaying training until adolescence. 
Teachers are responsible for providing realistic expectations to students as to what career stresses are involved in singing. This is where networking on behalf of the student is important. Students need to have contact and exposure to singers at all levels of their career and not be cloistered in the incorrect notion that they need to be protected or owned. A teacher who encourages viewing and participating in many singing events provides a realistic view of performance. Students can watch more advanced singers to give them a model to aspire to. They can also see that communication, not perfection is the aim of a good performance. Seeing singers have an 'off-day' is part of the framework of the nature of live performance for young singers.

Teachers may be partly responsible for the singer's anxiety either by overemphasizing or negatively perceiving the physiological symptoms related to performance. Most of the physical responses to anxiety are not individually responsible for undermining a student performance. The symptoms themselves are, for the most part, mildly irritating or distracting rather than debilitating. Where they become an issue is in the perception that their presence should activate fear and initiate failure. Similar symptoms re-interpreted as pre-performance excitement can allow the student to focus on the task of performing instead of needing to conquer the symptoms. Incorporating the anxiety management techniques into training and performance is as logical as warming up and writing programme notes. Another pedagogical approach is to ignore the symptoms entirely with the popular misconception that they will go away with experience. The student may then interpret the symptoms as a problem or even feel that they are not good enough to perform until they feel calm. This approach does not acknowledge the fact that MPA may begin at any point in a singer's career.

The acquisition of performance coping skills can be gradual and progress in parallel with the vocal training process. Teachers need to individually assess whether examinations and competitions are suitable to the adolescent student. Perhaps it is necessary to accustom a young singer to the assessment process, but it must be acknowledged that the pressure of constant testing does not suit everyone. The number and significance of assessments increase markedly once students attend secondary school. If the adolescent singer finds the level of criticism difficult to manage they may become isolated from the audience's enjoyment of their singing and 
the communicative aspects of music. Although examining may be justified to check development and therefore provide targeted assistance as necessary or even for motivational purposes, some singers find the awareness of a superior (whether in the form of music teacher, adjudicator or conductor) undermines their confidence. Balancing status is challenging for voice teachers. On the one hand, singing is a very personal task that might be easier when the adolescent singer sees their teacher as a coach without a higher status. A coach can help a singer develop his or her own character through the process of learning to sing. However, the balance might be too delicate when it comes to decisions for which the teacher, with their knowledge and training, should be responsible. Relinquishing the traditional teacher/student relationship is therefore only possible on a day-to-day basis if the fundamental superiority of the teacher/coach is acknowledged overall and the adolescent concerned has a high level of intrinsic motivation.

\section{$\underline{\text { Attitudes to MPA }}$}

What should our attitude to performance anxiety be? Don Greene (2001) dislikes the term performance anxiety. He sees it as a normal level of energy that should not be suppressed or made to sound like a problem. In terms of research, 'performance anxiety' is the term accepted by academics but that does not necessarily make it ideal for use in the studio. The language is definitely an issue. Student singers are said to 'suffer' from either 'stage fright' or 'performance anxiety', which likens it to a disease. One approach could be to consider avoiding the term unless the students initiate it themselves.

Although the label is not directly helpful, 'stage fright' clearly exists in popular consciousness. Post-performance discussions with students often centre on their 'nervousness'. Teachers need to be clear when it would be helpful to use the term: 'performance anxiety' actively. For example, a normally diligent student with an upcoming examination may be avoiding practice and feeling tired all the time. Suggesting MPA as a possible cause will be a relief to the adolescent singer whose parents think they are being lazy. If the student remains unaware of the causes of their anxiety, they risk entering the examination unprepared. That experience may cause further anxiety along with guilt for not doing their best. An assessment of cognitive 
MPA indicates further attention needs to be given to support this student. Challenging their perfectionism and supporting a programme of study skills allows the adolescent singer to progress. Support and progress are the keys to not damaging a student with a residual negative self-image due to MPA.

Over recent decades, vocal pedagogy has shifted towards discussing vocal technique in real terms. If we accept the value of students understanding the physiology of singing, we should be able to accept adolescents becoming aware of performance psychology. Like so much involved in teaching, the attitudes we hold have more influence than the actual words we say. A teacher who has clear understanding of tools for assessing and treating MPA will not see it as a problem. The term 'performance anxiety' is neutral; having no inherent value. Any emotional response to it by adolescents is learned. 


\section{Conclusion}

Techniques for managing MPA are as varied as the adolescent singers who experience it. No two adolescent singers are the same. Bronfenbrenner's model shows the effect of the central individual on the experience and environment (refer Fig.1). Teachers in the studio interact with the individual adolescent singers in the microsystem and need to adjust their approach according to that individual's needs. As a personal experience (albeit with an audience in attendance) MPA occurs at the microsystem level. Therefore the individual singer has the major role in the experience of MPA. Knowing this should inspire optimism within both adolescent singers and their teachers alike as to how effective their own efforts to manage MPA might be. At the level of immediate environment, teachers may develop awareness of the effect their personal attitudes and knowledge of performance psychology has on their adolescent students' experience of MPA. Teachers are therefore not only assessing adolescent singers but also their own knowledge, objectivity in assessment and flexibility in teaching techniques. By developing positive interactions in the mesosystem (communication with parents, peers and other teachers) voice teachers can encourage consistency of approach to and understanding of the adolescent singer experiencing MPA. At the exosystem level (interactions which do not include the adolescent singer) teachers can actively increase their knowledge of MPA and the communication of experiences between each other both through organisations and informal networking. The ecological systems model shows that these actions may also positively affect wider cultural norms and social expectations in the macrosystem.

The effective application of solutions to MPA is necessarily preceded by clear assessment of the adolescent singer. Only then can systematic, targeted treatment be incorporated into their training. One of the greatest challenges for voice teachers is being able to work through a targeted structure of treatment and training with limited teaching time. Weekly lessons can become haphazard and it is difficult to sustain developmental continuity unless an adolescent singer is extremely self-disciplined. Performance experiences that are beyond the adolescent singer's level of preparation occur at various times which can have a negative effect on their confidence. 
'Intensive' courses during study breaks may be the way to provide a focused programme of training in performance techniques and anxiety management. Seeing students individually and in group-sessions for a set number of lessons means that tasks can be worked through systematically and reinforced with exercises at home.

Recommendations for future study include looking at the effect studying voice at school has on adolescent singers with MPA. What are the differences between those who learn and are assessed at school, those who learn privately and those who do both? Further work is needed to provide teachers with a working model that can be incorporated into the studio. Knowing is not the same as doing. Further investigation and practice is needed to detail the effectiveness of the techniques on this particular group. But action is needed as MPA does not necessarily disappear of its own accord. 


\section{Appendix 1}

\section{Assessment (Emmons and Thomas, 1998, pp.151-153)}

\section{Exercise 1}

On the following arousal scale write down where you think you usually are in these three time frames: before performance, during performance, and after performance.

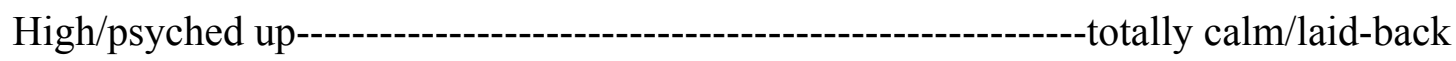

$\begin{array}{llllllllll}10 & 9 & 8 & 7 & 6 & 5 & 4 & 3 & 2 & 1\end{array}$

\section{Exercise 2}

Write down just how anxious a person you are. Are you a real worrier? Do you worry only a little? Are you very calm, laid-back? Or do you sit somewhere in the middle? Make some notes about your symptoms of anxiety as you go along.

\section{Exercise 3}

Think back to an ideal performance of yours, one that you would like to repeat, one in which you performed very well. Think of all the things you did before your performance, including eating, drinking, sleeping, vocalizing, physical warm-up, and traveling. Note how you felt and what you were focusing on at the time. Also recall how you felt during the performance. Work in as much detail as you can. Not only does this form your own ideal arousal zone, but it also will give you some idea of how you achieved this ideal zone. Now all you have to do is learn the skills of managing and controlling anxiety. Then you will be able to repeat this pattern of getting in the zone time after time. 


\section{Exercise 4. Recognizing your symptoms}

The symptoms shown in the chart accompanying this exercise are some of those that performers have recognized as present when they feel either physical or mental anxiety. Use this chart as a reference to help you recognize your own symptoms of anxiety. As you can see, many are very obvious. Indeed, not all somatic symptoms are negative. Pounding heart, increased respiration, and increased adrenaline need not be negative signs. However the presence of other physical symptoms together with mental symptoms may mean that your level of arousal has gone too high. You should then take some action to lower the level so that it doesn't interfere with your performance.

Check to see which of these symptoms you may or may not have; then double-check to see whether you do need to take some action about your anxiety (adapted from Martens, 1987, p.112).

Cognitive (Mental)

Indecisiveness

Worry

Feeling of being overwhelmed

Inability to concentrate

Feeling out of control

Narrowing of attention

Loss of confidence

Forgetfulness

Fear

Irritability
Somatic (Physical)

Pounding heart

Profuse sweating

Increased respiration

Decreased blood flow to the skin

Increased muscle tension

Dry mouth

Trembling and twitching

Frequent urination

Nausea

Loss of appetite

Sleeplessness

Increased adrenaline 


\section{Appendix 2}

\section{Centering Instructions (Greene p.167)}

\section{Step 1: Form a clear intention}

What you intend to accomplish when you come out of the Centering. "I am going to..."

Step2: Pick a Focus Point

Select an external point lower than eye level before closing your eyes.

Step 3: Start Abdominal Breathing

Breathe slowly and deeply into your lower stomach (3 to 7 breaths).

Step 4: Scan for Muscle Tension

Check your key muscles one at a time, then breathe out tension (3 to 7 breaths).

Step 5: Be at Your Center

Focus down to your center (3 to 7 breaths).

Step 6: Repeat Your Process Cue

Say it until you are in your right brain: seeing it, feeling it, hearing it (3 to 7 breaths).

Step 7: Direct Your Energy to Your Point

Let the energy flow from your center to your focus point. Go for it! 


\section{Appendix 3}

\section{$\underline{\text { Cognitive exercises }}$}

Emmons and Thomas (1998) ask the singer to identify what kinds of things cause them to be mentally anxious. They divide them into three categories:

1. Worries about perceived demands of others.

2. Worries about your own ability.

3. Worries about the consequences of the performance.

Once you have identified the type it is simply a matter of focusing positive self-talk and affirmations. The aim is to train your mind to respond to the challenge of performance rather than the threat.

Secondly they suggest using mental imagery to reduce anxiety. Practice visualizing yourself performing well and with confidence. The other way to use imagery to control arousal is to visualize scenes that relax you. For example running water, or riding in a hot air balloon. If you have a special person that always makes you feel safe and who is very supportive of your work you can picture them in the audience.

Thirdly they outline three breathing exercises to help reduce mental anxiety:

\section{Exercise 1. Even Breathing}

Inhale evenly through the nose, taking four or five long deep breaths. Exhale to the same count through the mouth. While exhaling, focus on your relaxed hands. Repeat the process, but this time, on the exhalation, focus on your relaxed shoulders, jaw, or neck. You can repeat this process for as long as you want, depending on the amount of time you have. When you become very good at it, one or two breaths will do the job for you. This means, of course, that you do have to practice this routine as often as you can. Only in this way will it work when you need it! 


\section{Exercise 2. Ratio Breathing}

Inhale deeply through your nose to the count of 5. Exhale through the mouth to the count of 10. During the exhalation, focus on watching yourself perform well, beginning with a bang, singing a small part of your aria very well indeed, or even making an entrance. This type of breathing is termed ratio, because the length of the exhalation should always be double that of the inhalation, for example, $3: 6,4: 8,5: 10$, et cetera. Ratio breathing combines relaxation and concentration. On the exhalation you can focus on anything that will help you to feel good and reduce your anxiety. Ratio breathing has been used very effectively both before and during performance.

\section{Exercise 3. Power Breathing}

This section is adapted from Saul Miller, Performance under Pressure, 1992. This method of breathing asks you to focus during both the inhalation and the exhalation. As you inhale, you focus on breathing in your own power. Think: This is my own power I am inhaling. As you exhale, use your power to focus on feeling good, calm, and in control. Say to yourself: This is my performance; I am well prepared. While you practice this skill, you should get accustomed to the feelings associated with being in control of your mental anxiety. The more you practice, the more you will be able to use these skills when you want to, either before or during performance. 


\section{Appendix 4}

\section{Somatic exercises}

Practicing a method of deep relaxation can reduce tension in the lead-up and recovery from challenging performances. This could be yoga, massage, meditation or the following exercise from Edmund Jacobsen's Progressive Muscular Relaxation (1974) adapted by Emmons and Thomas (1998).

1. Get into a comfortable, supported position, sitting or lying.

2. Close your eyes, relax, and focus on your breathing. Allow the breathing to become a steady rhythm. As you continue to breathe out, let the tension drain from the body until you are fully relaxed.

3. Clench your right fist tighter and tighter, focusing on the tension in your fist, hand, and forearm. Now relax by slowly opening your fingers. Feel the looseness in your right hand and arm; feel its heaviness. Repeat this procedure with the left fist and arm, always paying special attention to the differences between relaxation and tension.

4. Now tighten your buttocks and thighs. Relax; feel the difference. Focus on your right leg. Curl your toes downward, tensing the calves; focus on the tension. Slowly relax. Tighten the muscles in your whole leg; hold the tension; then allow the muscles to relax completely. Allow the leg to go heavy and relax deeply. Repeat this procedure. Once again, pay special attention to the contrast between the relaxation and the tension. Repeat with your left leg. Feel the heaviness throughout your lower body. Relax feet, ankles, calves, knees, thighs, and buttocks.

5. Now focus on your face, neck, and shoulders. Wrinkle your forehead as tight as you can. Relax and smooth it out. Clench your jaw; bite hard; focus on the tension. Relax and feel the contrast between tension and relaxation. Shrug your shoulders; hold the tension. Now relax them; drop them back until you can feel the heaviness and the relaxation spreading throughout your neck, face, and shoulders. This should be deep relaxation. 
6. Focus on allowing your entire body to relax. Enjoy the feeling of heaviness from head to toe. Breathe in; hold your breath; feel and notice the tension. Exhale and feel the relaxation. Repeat several times, allowing the body to become more relaxed each time you exhale. Drain the tension away.

7. Enjoy the feeling of complete relaxation for some minutes. Become aware of the feeling of calmness in your whole body. You are now completely at ease and free from tension.

8. Now allow yourself to stretch parts of the body slowly, gradually becoming aware again, and open your eyes. As you do this, also tell yourself how wonderful you feel, how relaxed and at ease with yourself (Emmons, 1998, pp.70-71).

In addition to practicing a preferred method of deep relaxation, Emmons also advises developing techniques for momentary relaxation to manage your arousal level both immediately before and during performance. The isolation technique outlined above can also be used swiftly to scan the body for non-essential tension and allow those areas to recover the heavy, released sensation you are accustomed to sensing in practice. Although breathing techniques are also suggested, they are of little use during performance as there is seldom opportunity to return to a regulated breathing pattern whilst singing. 


\section{Bibliography}

Balk, David E. Adolescent Development: Early Through Late Adolescence. USA: Books/Cole Publishing Company, 1995.

Berglas, Dr. Steven. The Success Syndrome: Hitting Bottom When You Reach the Top. NY: Plenum Press, 1986.

Berzonsky, Michael D. 'Theories of Adolescence'. Adolescent Development: The Essential Readings. Oxford: Blackwell Publishers Ltd., 2000, pp.11-27.

Beunan, G., \& Malina, R.M. Growth and physical performance relative to the timing of adolescent spurt'. K.B.Pandolf (Ed.) Exercise and sport sciences reviews. NY: Macmillan, 1988.

Bronfenbrenner, Urie. The Ecology of Human Development: Experiments by Nature and Design. Cambridge, MA: Harvard University Press, 1979.

Bronfenbrenner, Urie. 'Ecological Systems Theory'(1992). Making Human Beings Human: Bioecological Perspectives on Human Development. Urie Bronfenbrenner, Ed. California: Sage Publications, Inc., 2005. pp.106-173.

Broude, Gwen J. Growing Up: A Cross-Cultural Encyclopedia. Santa Barbara: ABCCLIO, Inc., 1995.

Bruno, Frank J. The Family Encyclopedia of Child Psychology and Development. NY: John Wiley \& Sons, Inc., 1992.

Buechler, Sandra \& Izard, Carol. 'Anxiety in Childhood and Adolescence'. Handbook on Stress and Anxiety. Irwin L. Kutash and Louis B Schlesinger (Eds.). San Francisco: Jossey-Bass Inc., 1980.

Campbell, Don. The Mozart Effect. NY: HarperCollins, 2001. 
Côté, James E., 'Was Mead Wrong About Coming of Age in Samoa? An Analysis of the Mead/Freeman Controversy for Scholars of Adolescence and Human Development'. Gerald Adams (Ed.).Adolescent Development: The Essential Readings. Oxford: Blackwell Publishers Ltd., 2000, pp. 301-336.

Dacey, John and Margolis, Deborah. 'Psychosocial Development: Adolescence and Sexuality'. Kathleen M. Thies \& John F. Travers (Eds.). Handbook of Human Development for Health Care Professionals. Massachussetts: Jones and Bartlett Publishers, Inc., 2006, pp. 191-218.

David, Marilee. The New Voice Pedagogy. Maryland: The Scarecrow Press, Inc., 1995.

Dews, C.L.Barney \& Williams, Martha S. 'Student Musicians' Personality Styles, Stresses, and Coping Patterns.' Psychology of Music, Vol. 17, 1989, pp. 37-47.

Eckrich, Jean \& Strohmeyer, Scott. 'Motor Development'. Kathleen M. Thies \& John F. Travers (Eds.). Handbook of Human Development for Health Care Professionals. Massachussetts: Jones and Bartlett Publishers, Inc., 2005, pp 161-190.

Elkind, David. 'Egocentrism in Children and Adolescents'. Children \& Adolescents: Interpretive Essays on Jean Piaget. NY: OUP, 1970, pp. 50-71.

Elkind, David. 'Cognitive Structure and Experience in Children and Adolescents'. Children \& Adolescents: Interpretive Essays on Jean Piaget. NY: OUP, 1970, pp. $72-$ 80. from "Egocentrism in Adolescence," Child Development, 38, 1967, 1025-34.

Emmons, Shirlee \& Thomas, Alma. Power Performance for Singers - Transcending the Barriers. New York: Oxford University Press, 1998.

Erikson, Erik. Childhood and Society. $2^{\text {nd }}$ ed. NY: Norton, 1950.

Fleming, Renee. The Inner Voice - The Making of a Singer. NY: Penguin, 2004. 
Folkman, S. \& Lazarus, R.S. 'An Analysis of Coping in a Middle-aged Community Sample'. Journal of Health and Social Behavior, 21, 219-239. 1980.

Freud, Anna. (1972). Adolescence. In J. F. Rosenblith, W. Allinsmith, \& J.P. Williams (Eds.). The causes of behaviour ( $3^{\text {rd }}$ ed.), pp. 317-323. Boston: Allyn \& Bacon.

Gallwey, Timothy W. Inner Tennis: Playing the Game. New York: Random House, Inc., 1976.

Garden, Mary. 'The Know How in the Art of Singing', in Brower and Cooke (1920), Q.V., pp.62-7.

Goldstein, Avram. 'Music/Endorphin Link', Brain/Mind Bulletin. 25 Jan and 11 Feb 1985: pp. 1-3.

Goodburn, Elizabeth A., and Ross, David A. (1995). "A Picture of Health: A Review and Annotated Bibliography of the Health of Young People in Developing Countries." Published by the World Health Organization and UNICEF. Available from: http://whqlibdoc.who.int/hq/1995/WHO FHE ADH 95.14.pdf. Accessed 24 September 2007.

Greene, Don. Audition Success: An Olympic Sports Psychologist Teaches Performing Artists How to Win. NY: Routledge, 2001.

Gruner, Walter. 'Voice Production and Body Co-ordination'. Tensions in the Performance of Music. London: Kahn \& Averill, 1978, pp. 56-73.

Haberg, Karen A. Stage Presence From Head to Toe. Maryland: The Scarecrow Press, Inc., 2003. 
Haubenstricker, J.L., Wisner, D., Seefeldt, V., \& Branta, C. 'Gender differences and mixed-longitudinal norms on selected motor skills for children and youth. Journal of Sport \& Exercise Psychology: 1997 NASPSPA Abstracts, 19, S63.

Inhelder, B. and Piaget, Jean. The Growth of Logical Thinking. NY: Basic Books, 1958.

Izard, Carroll E. 'Anxiety: A Variable Combination of Interacting Fundamental Emotions.' Anxiety: Current Trends in Theory and Research. NY: Academic Press, 1972, pp.55-106.

Jacobson, Edmund. Progressive Muscular Relaxation. Chicago: University of Chicago Press, 1929. (1974, Midway Reprint).

James, William. The Principles of Psychology. Chicago: Encyclopaedia Britannica, 1952.

Kenny, Dianna T. \& Davis, Pamela \& Oates, Jenni. 'Music performance anxiety and occupational stress amongst opera chorus artists and their relationship with state and trait anxiety and perfectionism.' Journal of Anxiety Disorders. Vol. 18, no.6, 2004, pp. 757-777.

Kohut, Daniel L. Musical Performance - Learning Theory and Pedagogy. New Jersey: Prentice-Hall, Inc., 1985.

Kutash, Irwin L. 'Prevention and Equilibrium-Disequilibrium Theory'. Handbook on Stress and Anxiety. San Francisco: Jossey-Bass Publishers Inc., 1980. pp 463-473.

Ladd, George. 'Adolescent Anxiety: Developmental Context and Cognitive Perspectives'. Kathleen M. Thies and John Travers (Eds.). Handbook of Human Development for Health Care Professionals. Massachussetts: Jones and Bartlett Publishers Inc., 2006, pp. 339-354. 
Larson, Reed. 'The High School "Junior Theme": as an Adolescent Rite of Passage'. Adolescent Development: The Essential Readings. Gerald Adams (Ed.). Oxford: Blackwell Publishers Inc., 2000, pp. 224-240.

Lazarus, Richard S. Stress and Emotion: A New Synthesis. NY: Springer Publishing Company, Inc., 1999.

Lehrer, Paul. 'Performance Anxiety and How to Control it: A Psychologist's Perspective'. Tensions in the Performance of Music. Carola Grindea (Ed.). Lodon: Kahn \& Averill, 1978. pp 134-152.

Marchant-Haycox, Susan E. and Wilson, Glenn D. 'Personality and Stress in Performing Artists.' Peron. Individ. Diff. Vol. 13, no. 10, 1992, pp. 1061-1068. Pergamon Press Ltd.

Martens, Rainer. Coaches Guide to Sport Psychology. Champaign, Illinois: Human Kinetics, 1987.

Miller, Saul. Performance under Pressure. Toronto/Montreal: McGraw-Hill Ryerson, 1992.

Miller, Staci Renee \& Chesky, Kris. 'The Multidimensional Anxiety Theory: An Assessment of and Relationships Between Intensity and Direction of Cognitive Anxiety, and Self-confidence Over Multiple Performance Requirements Among College Music Majors.' Medical Problems of Performing Artists, Vol.19, no. 1, 2004, pp. 12-20.

Osborne, Margaret S. \& Kenny, Dianna T. 'Development and validation of a music performance anxiety inventory for gifted adolescent musicians.' Journal of Anxiety Disorders. Vol. 19, 2005, pp. 725-751.

Paikoff, R.L. \& Brooks-Gunn, J. 'Do parent-child relationships change during puberty?' Psychological Bulletin. Vol. 110, 1991, pp. 47-66. 
Provost, Richard. The Art \& Technique of Practice. San Francisco: Guitar Solo Publications, 1992.

Roland, David. The Confident Performer. NH: Heinemann, 1997.

Sandgren, Maria. 'Becoming and being an opera singer: Health Personality and skills.' Sweden: Stockholm University, 2005, available from http:/www.divaportal.org/diva; accessed 24 March 2006.

Schneier, F.R. 'Clinical Practice. Social Anxiety Disorder'. New England Journal of Medicine. Vol. 355, no. 10, 2006, pp. 1029-36.

Seiffe-Krenke, I. Stress, coping, and relationships in adolescence. Mahwey, NJ: Erlbaum, 1995.

Sell, Karen. The Disciplines of Vocal Pedagogy: Towards an Holistic Approach. Aldershot, England: Ashgate Publishing Ltd., 2005.

Selye, Hans. Stress without Distress. Philadelphia: J.B. Lippencott Company, 1974.

Selye, Hans. 'The Stress Concept Today'. Handbook on Stress and Anxiety. San Francisco: Jossey-Bass, Inc., 1980, pp. 127-143.

Sprinthall, N.A., \& Collins, W.A. Adolescent Psychology: A Developmental View. Reading, MA: Addison-Wesley, 1984.

Suinn, Richard M. \& Deffenbacher, Jerry L. 'Behavior Therapy'. Handbook on Stress and Anxiety. San Francisco: Jossey-Bass, Inc., 1980, pp. 392-412.

Steptoe, Andrew. 'Stress, Coping and Stage Fright in Professional Musicians.' Psychology of Music. Vol. 17, no. 1, 1989, pp 3-12. 
Thies, Kathleen. 'Development of Children with Chronic Illness'. Kathleen M. Thies \& John Travers (Eds.). Handbook of Human Development for Healthcare Professionals. Massachussetts: Jones and Bartlett Publishers, In., 2006, pp. 381-410.

Tolan, Stephanie. www.stephanietolan.com/spiriituality.htm. Accessed 21/11/07. 2007.

Tomatis, Alfred. The Ear and the Voice. Lanham, MD: Scarecrow Press, 2005. Originally published 1988.

Travers, John. 'Current Views of Life Span Development'. Kathleen M. Thies \& John Travers (Eds.). Handbook of Human Development for Health Care Professionals. Massachussetts: Jones and Bartlett Publishers, Inc., 2006, pp. 3-18.

Unger, Rhoda. 'Imperfect Reflections of Reality: Psychology Constructs Reality.' R.T. Hare-Mustin\& J. Marecek (Eds.). Making a Difference: Psychology and the Construction of Gender. New Haven, CT: Yale University Press, 1990, pp. 102-149.

Vygotsky, L.S. Mind in Society. Cambridge, MA: Harvard University Press, 1978.

Wink, Joan \& Putney, LeAnn. A Vision of Vygotsky. Boston: Allyn \& Bacon, 2002.

World Health Organization, www.org.un.in/Jinit/who.pdf. Accessed 20/11/07. 